\title{
DETERMINACIÓN ECONÓMICA Y JURÍDICA DE LA CONDUCTA
}

I

Una de las principales fronteras que mantiene la ética con los determinantes de la conducta moral, es la que linda con la economía; su influencia es muy considerable, pues el hombre efectúa gran parte de sus actos acatando necesidades materiales de la vida y procurando la adquisición de los medios para satisfacerlas. De la gran influencia que ejerce el factor económico en la conducta se desprende la estrecha relación entre ética y economía, que nos proponemos analizar en las siguientes páginas.

Debemos señalar, ante todo, la doble posición que se adopta comúnmente con perfiles antagónicos, en relación a este problema; por una parte, se tiene la posición tradicionalista o absolutista de quienes consideran que la moral debe estar fundada en los más sólidos principios, sin que el vaivén de las alternativas económicas deba afectarle en lo más mínimo; por otra parte, la segunda posición es contraria a la primera, o sea relativista o revolucionaria, reconociendo la imposibilidad de sustraer totalmente nuestros actos a la influencia de la economía, afirmando en consecuencia que toda forma de conducta es justipreciable únicamente si se tiene en cuenta dicho factor. Así por ejemplo, los del primer bando sostendrán que una virtud como la honradez debe resistir cualquier embate de las adversidades, en tanto que los del segundo afirmarán la relatividad de dicha virtud, explicando en un momento dado su violación por efecto de las necesidades económicas.

Vamos a caracterizar ambas posiciones en los siguientes términos:

a) Posición absolutista. Sostiene que la conducta debe estar fincada en virtudes absolutas, con independencia del influjo que puedan tener los factores económicos en la conducta.

b) Posición relativista. Afirma la imposibilidad de aislar el comportamiento de sus determinantes económicos; el ejercicio y valor de la conducta quedan sujetos a la determinabilidad de la economía.

Ahora bien, frente a estas dos posiciones interesa destacar que cada una tiene su propia justificación, aunque ninguna de modo incondicionado; en cada caso encontramos un punto de vista que puede justificarse dentro de su peculiar alcance, mas no así cuando pretende negar la posición contraria. Los del sector absolutista tienen razón en sostener que la virtud debe estar templada en el crisol de las adversidades, pero no vemos cómo pudiera evitarse definitivamente cualquier violación a la honradez, cometida pará sa- 
tisfacer una necesidad emergente, que orillaría al más honesto de los hombres a cometer una falta o un delito a fin de procurar los recursos más elementales para él y los suyos.

Casos de este tipo se presentan continuamente en una sociedad como la nuestra, plagada de injusticias y necesidades insatisfechas; los tribunales y agencias policiacas toman noticia constantemente de dichos sucedidos y en ellos se ha impuesto ya como criterio de apreciación tener en cuenta el nivel económico de los individuos, no sólo en lo concerniente a determinado acto inmoral o delictivo, sino también por el ambiente social y cultural en que se vive, influido en gran parte por los factores económicos.

En este caso, como en todos los demás de la moralidad, no se puede establecer una norma absoluta, pero tampoco se debe caer en el libertinaje por falta total de normas. La estimación de la conducta según la influencia del factor económico debe efectuarse a través de los casos concretos, examinando las circunstancias que lo determinan. No podemos decir a rajatabla: "la conducta debe ser independiente de las necesidades materiales"; ni tampoco "la conducta está incondicionalmente sujeta al imperio de dichas necesidades". La única verdad terminante y definitiva es que cada caso debe estudiarse en sus propias circunstancias, con el sentido peculiar que hace de él un acto único al cual debe aparejarse un juicio estimativo de singularidad. Como el análisis casuístico ocupa la parte concreta de la ética, trataremos de examinar el concurso de dichas circunstancias, para contribuir a una más clara definición y valoración de la moralidad.

La gran influencia que tiene el factor económico en la conducta, se refrenda al observar que la gran mayoría de nuestros actos se promueven por la necesidad y el deseo de adquirir bienes materiales. Obsérvese que hemos dicho la necesidad y el deseo, significando que la adquisición de tales bienes puede obedecer a necesidades más o menos apremiantes, o al cumplimiento de deseos más o menos superfluos.

La búsqueda de bienes materiales tiene diversos grados de acción, según el caso. En primer término está la satisfacción de las necesidades urgentes, como el sustento, el vestido y la habitación; pero la gran mayoría de los hombres que forman la sociedad actual, y principalmente los que habitan en una gran ciudad, no se conforman con tener el mínimo estricto para satisfacer sus necesidades apremiantes, sino desean elevar su nivel de vida con el disfrute de otros, bienes, y, por consiguiente, con la creación de nuevas necesidades. Aun el más modesto trabajador que habita en una ciudad civilizada, anhela tener un superávit de objetos que proporcionạn cierta comodidad adicional en la vida, y no le satisfará exclusivamente el mínimo para subsistir. Contribuye en gran parte a fomentar este deseo, la emulación que inspira ver a la mayoría de los hombres con el mismo anhelo de comodidad y superación material que llega muchas veces al lujo superfluo y al incon- 
trolado derroche, lo cual tiene por objeto hacer una abierta ostentación de superioridad ante los demás, exhibiendo mayor cuantía de propiedades. El promedio de capacidad económica de un individuo o de una familia, así como su participación en la economía diaria, es lo que se ha llamado el nivel de vida y constituye la unidad tipológica que muestra el promedio de capacidad adquisitiva en los individuos y las diversas capas sociales.

En estas condiciones, distinguiremos tres grandes niveles de vida para sendos estratos de la sociedad, tres prototipos en la producción y satisfacción de necesidades materiales. El primero contiene el mínimo posible de elementos para subsistir, llenando apenas las necesidades primarias, y le llamaremos indigencia. El segundo procura un nivel más decoroso, con cierto desahogo material mediante el cumplimiento de ciertas necesidades adicionales, y le llamaremos suficiencia. El tercero procura los bienes en exceso mediante objetos superfluos y accesorios, con un nivel de vida que designaremos como opulencia. Veamos cuáles son los principales rasgos de cada uno.

a) Indigencia. El primer nivel corresponde a la llamada "gente pobre", y como su nombre lo indica, consiste en una vida precaria, de absoluta pobreza, con alimentación insuficiente, indumentaria escasa y mala habitación; la indigencia va acompañada generalmente de ignorancia, insalubridad y promiscuidad, que rebajan al hombre en el aspecto cultural, biológico y social, respectivamente. Su efecto ético y psicológico es una depresión permanente que impide a quienes la padecen salir de ese pantano de miseria, terminando por ahogarse completamente en él. Esto ha hecho pensar, muy equivocadamente, que la gente pobre lo es por gusto, que le complace debatirse en la miseria y no sale de ella por abulia y pereza, justificando la indigencia por el trabajo de superarse a base de esfuerzo personal.

b) Suficiencia. El segundo nivel de vida corresponde al hombre normal de nuestra sociedad; en términos generales, es el nivel más recomendable para obtener una situación justa y ocupa un término medio que permite extenderse a la gran mayoría de la humanidad. Bien llevado, el nivel de suficiencia puede convertirse en un auténtico ideal ético y sociológico de la vida económica. El hombre adaptado a una razonable suficiencia procurará tener un guardarropa normal, probablemente con cierta apariencia estética, querrá habitar un departamento decoroso o una pequeña residencia y procurará ser el propietario de la misma; querrá formar algún patrimonio familiar que le dé cierta seguridad, más allá de sus ingresos normales; para él, la alimentación no es únicamente un medio de nutrirse, sino también de disfrute y complacencia; deseará poseer también los objetos que ha producido la técnica moderna en gran escala industrial para satisfacer ciertas necesidades suplementarias y deseos razonables de comodidad; en el aspecto cultural procurará un mínimo para él mismo y querrá que sus hijos escalen un peldaño más en la carrera de la competencia social. 
c) Opulencia. Por último, el tercer nivel de vida, o sea la opulencia, consiste en una situación que tiene en demasía todos los elementos materiales. El tipo de personas que lo disfrutan poseen una amplia fortuna, permitiéndose la posesión excesiva de propiedades, y un gran número de satisfactores de índole diversa que proporcionan el más alto nivel económico de vida mediante el sobrado disfrute de los numerosos adelantos técnicos y comodidades que proporciona la vida moderna, ampliamente deseados por el hombre normal de nuestra sociedad. En su extremo, la opulencia se convierte en ofensiva ostentación y constituye un reto a la sociedad, una ofensa a quienes se debaten en la pobreza, una burla a los principios de equidad que imperan en la conciencia del hombre.

La formación de niveles diferentes de vida dentro de una misma sociedad va acompañada por diferencias de fortuna, bienestar y de todo orden, incluyendo en primer término la posición social que deriva de la posición económica, de acuerdo con las convenciones de la sociedad actual. También se producen implicaciones psicológicas, pues quien no tenga satisfechas sus necesidades urgentes se verá en una grave situación de apremio; su personalidad y su conducta sufrirán grave distorsión respecto del estado moral de lo que él mismo podría ser o hacer en otras condiciones. Otra clase de resultantes son las jurídicas, puesto que un individuo en situación de apremio estará en continuo riesgo de cometer actos delictivos, como se ha comprobado hasta la saciedad en el estudio de la conducta. Igualmente se verá complicada la salud física, el nivel cultural, las creencias religiosas, y para decirlo en una palabra, todas y cada una de las manifestaciones del hombre.

Debido a esta cabal proyección de la actividad económica en todos los órdenes de vida, el estudio y la resolución de sus problemas ha cobrado una importancia de primer orden; nunca como ahora se había clamado tan intensamente por la revisión del sistema económico y su transformación en todo lo que sea necesario para instaurar un orden justo. La tendencia de las doctrinas económicas consiste en procurar la realización de la justicia mediante una equitativa distribución de la riqueza, pues sólo así se logrará instaurar sobre base sólida a la justicia social, política y jurídica, que tienen como derecho todos los hombres. Mientras no exista un respaldo económico, los principios de equidad y las teorías sobre lo justo quedarán como infecunda especulación, pues habrá una clase social más poderosa que tomará en sus manos el timón político y lo pondrá al servicio de sus propios intereses, en detrimento de los ajenos.

La resolución del problema económico adquiere así un vigoroso perfil ético y viene a sumarse al establecido en el orden sociológico, político, jurídico, histórico y religioso. En la actualidad no se toma a la economía simplemente como un medio de aumentar la producción, regular el mercado 
o perfeccionar el sistema financiero. Se trata principalmente de una cuestión moral porque en el fondo subsiste la preocupación de hacer justicia a través de ordenamientos sociales inspirados en el principio de igualdad: igualdad en derechos, en obligaciones, en oportunidades y en perspectivas para todos los hombres; y lo que es más definitivo, en dignidad humana. Por ello es cuestión de dignidad y no solamente de confort hacer las reclamaciones necesarias para instaurar un orden justo en la economía; también es cuestión de dignidad y no sólo de necesidad, reclamar el derecho al trabajo, a la retribución justa, al respeto personal, a la solidaridad colectiva, simultáneamente con el rechazo al derecho minoritario, oligárquico y aristocrático, que culmina en el dramático contraste entre la indigencia más precaria y la opulencia más ostentosa. Contra todo ello se han lanzado voces de protesta que encierran un ingente clamor de justicia, como el flamigero anatema de Salvador Díaz Mirón, cuya palabra poética supo exigir la justicia económica proclamando que: "Nadie tiene derecho a lo superfluo mientras alguien carezca de lo estricto."

De acuerdo con los antiguos conceptos parecería que la influencia del factor económico en la conducta se limita simplemente a dar el incentivo para la adquisición de los bienes que satisfacen las necesidades materiales de la vida. Con ello no se fundamenta la implicación estética y todo parecería tener salida en la posibilidad de satisfacer dichas necesidades; desde este punto de vista, el hombre tendría un sentido desarrollado del trabajo, con cierta agudeza para elegir los bienes más adecuados a su propósito, mas no se deriva de ahí la intensa conexión moral que hemos advertido. En cambio, la moderna economía ha cambiado radicalmente ese concepto para subrayar su relación con la ética, la sociología y el derecho. Un aspecto importante de dicha relación consiste en que el conjunto de bienes que puede utilizar el hombre para satisfacer sus necesidades proviene del gran acopio de elementos que proporciona la naturaleza y que, aprovechados por el hombre con una elaboración que lleva a cabo mediante su trabajo y sus conocimientos, permite el cúmulo de actividades que hoy día destina a tal propósito.

Ahora bien, la cantidad de elementos de que dispone el hombre no es infinita sino limitada, constituye en principio una riqueza pública, y la posesión de una cantidad excesiva por parte de una sola persona o una minoría repercute necesariamente en la falta que pueda hacer a los demás. Si un solo individuo o unos pocos llegan a acumular grandes bienes materiales, el resto de la colectividad padecerá escasez de los mismos, provocándose el clásico desajuste que tanto ha preocupado a la economía: la excesiva acumulación de riquezas por una minoría y la correspondiente escasez para la mayoría. La forma como se encuentra distribuida la riqueza en la sociedad 
es un índice muy elocuente del estado económico, social y político que priva en la misma, teniendo una derivación a la ética que se canaliza en la justicia o injusticịa de dicha situación.

El sistema de la economía está basado en la intervención del hombre en el sistema de producción, a base de efectuar un determinado trabajo y percibir una remuneración a cambio de él. Comoquiera que dicha retribución es el medio de que dispone para satisfacer sus necesidades, surge inmediatamente la cuestión de cómo puede hacerse para que dicha retribución sea justa, atendiendo a las necesidades de la colectividad y al rendimiento de cada individuo. Se ha impuesto como forma práctica efectuar la retribución del trabajo por medio de cierta cantidad de dinero que se denomina salario y es la base para la riqueza personal y familiar de quien lo devenga.

De acuerdo con la necesidad que tiene el hombre de un medio económico para subsistir y por los merecimientos a que le hace acreedor su trabajo, la fórmula ideal para regular el poder adquisitivo parece descansar en un mandato muy sencillo: dar a cada quien un salario justo. Sin embargo, en ésta fórmula se encierra una incógnita que ha causado muchos y muy graves conflictos, pues, ¿en qué consiste lo justo del salario? La respuesta ya no es tan sencilla como la pregunta, si se tienen en cuenta la multitud de factores que intervienen en la economía, su relación con el trabajo y las necesidades de los individuos; por otra parte, el principio de solidaridad social obliga a ciertas concesiones y exigencias por encima del rígido criterio del trabajo personal y su retribución. Por todo ello, fijar un criterio de justicia para el salario se convierte en uno de los más arduos y complejos problemas que puedan pesar en la conciencia del hombre contemporáneo, llegando a tal punto la suma de implicaciones que resulta muy difícil fijar objetivamente el tan deseado criterio de justicia.

En torno a este problema se han pronunciado una serie de opiniones que tratan de ofrecer la solución, buscando la fórmula del salario justo, y por su innegable importancia es indispensable hacer cuando menos un señalamiento de las principales, por vías de ilustración y documentación. Veamos muy someramente en qué consisten.

"A cada quién según lo que trabaja". Ésta parece la fórmula más general y también la más acertada, pues indica que la retribución debe ser proporcional al trabajo. Podría expresarse en una disposición como la siguiente: A mayor trabajo, mayor salario; a menor trabajo, menor salario. Sin embargo, surge el interrogante de establecer la forma de apreciar el trabajo que se desarrolla; aquí intervienen factores de apreciación cualitativa que tienen en cuenta la calidad y no sólo la cantidad del trabajo desempeñado, pues si no fuera así se plantearían cuestiones como las siguientes: ¿Un picapedrero que trabaja más duramente que un médico debe ganar mayor salario que él? ¿Un cajero de banco que tiene los nervios en tensión debe ganar 
más que un artista, cuyo trabajo le reporta placer? Aquí se ve la dificultad para fijar la medida del trabajo y, por consiguiente, el monto del salario, de donde se ha propuesto una segunda fórmula.

"A cada quien según lo que sabe". En esta fórmula interviene un elemento diferencial de suma importancia, que distingue la calidad en el trabajo, basada principalmente en los conocimientos que se necesitan para desarrollarlo. Se dirá entonces que el salario debe ser mayor mientras más conocimientos se requieren para devengarlo. Pero aquí nace otra complicación y consiste en el criterio para definir la jerarquía de los diversos tipos del saber que se traducen en la preparación y capacidad del individuo. ¿Será por ventura el tiempo que le llevó en sus estudios profesionales? ¿O tal vez la cantidad de experiencia que ha acumulado durante toda su vida?

Pero puede ser que cierto tipo de conocimientos sean de tal índole que con poco estudio o escasa experiencia se llegue a rendimientos extraordinarios, de vital importancia para la sociedad; un individuo genial, con una preparación muy relativa puede hacer un descubrimiento de trascendental importancia. ¿Qué salario debe percibir aquel que una sola vez en su vida tiene un chispazo de inspiración y produce un invento de grandes repercusiones? Por otra parte, ¿el salario debe atender única o preferentemente al trabajo de orden práctico, que se traduce en producción material, o también cataloga en primera línea el trabajo de un artista o un filósofo, cuyos frutos se destinan a satisfacer el más elevado interés del espíritu? De ahí se ve que la segunda fórmula tampoco satisface completamente, y desemboca, igual que la anterior, en un aparente callejón sin salida.

" $A$ cada quien según sús necesidades". Debido en parte a la dificultad para fijar el criterio del salario justo según la cantidad y calidad del trabajo y en parte al deseo de establecer una norma completamente distinta, se ha llegado a la tercera fórmula que atendería, ya no al trabajo realizado, sino a las necesidades personales y familiares de cada individuo. La tendencia de esta nueva proposición consiste en nivelar al máximo la riqueza pública distribuyéndola con un óptimo criterio de justicia que consistiría en dar trabajo a todo el mundo y otorgar una retribución de acuerdo con las necesidades. Según esta fórmula, un ingeniero que desarrollara delicadísima labor de construcción en beneficio de la colectividad, a base de gran talento, preparación y experiencia, no percibiria mayor salario que uno de sus peones si éste tuviera necesidades más amplias por razones de familia, de salud o de cualquier otra especie. Como es de suponer, esta fórmula despierta grandes protestas por parte de quienes la consideren injusta y serán principalmente los que creen desempeñar un trabajo digno de mayor reconocimiento. Sin embargo, debemos indicar que, velada o abiertamente, la sociedad contemporánea se ha encaminado a grandes pasos hacia una fórmu- 
la como ésta, mediante una serie de controles que efectúa el Estado a fin de nivelar al máximo la distribución de la riqueza.

La cuestión del salario justo ha preocupado y sigue preocupando intensamente a quienes tratan de establecer una justicia social a base de la justicia económica; en realidad, éste es sólo uno de los aspectos que involucra el sistema económico en su relación con la ética, el derecho y la política, disciplinas que colocan al concepto de justicia como base de sus reflexiones. Durante mucho tiempo se debatió tan importante cuestión en el terreno de la mera ideología, principalmente de orden filosófico y religioso, queriendo fundamentar a base de huecas especulaciones metafísicas el derecho minoritario de la oligarquía aristocrática, que en la mayor parte de la historia ha tenido el dominio de los pueblos a base de ejercer la supremacía económica.

Sin embargo, las cosas han cambiado profundamente y después de numerosas luchas en el terreno ideológico y cultural, o en el de la política y las armas, amparándose en la idea de igualdad entre los hombres, todo parece apuntar a un futuro y definitivo entronizamiento de dicha idea para conducir los destinos de la humanidad. La transformación no se ha logrado a base de filosofías con un cariz igualitario, que reemplazarán a las del viejo tinte aristocrático, pues si la igualdad pudiera sustentarse únicamente sobre principios tan huecos como los que han defendido a la desigualdad, se habría hecho exclusivamente el reemplazo de una ideología artitraria por otra, pues tan infundado sería entonces afirmar la igualdad como la desigualdad entre los hombres.

El camino de la moderna economía ha sido básicamente el de la ciencia y las conclusiones que le han orillado al postulado de igualdad no obedecen a una simple filosofía, sino a la convicción más profunda que le han otorgado las ciencias que se ocupan de estudiar al hombre, acordes en sostener que la desigualdad tiende a esfumarse cada día más, y que es posible intentar a fondo la edificación de un sistema igualitario; el sentido de la civilización moderna consiste en disminuir las diferencias al mínimo, a cambio de aumentar las semejanzas al máximo, con el deseo de llegar a una franca igualdad en materia económica, jurídica y social.

La ciencia que recoge provechosamente todas las aportaciones que le brindan las demás disciplinas para proyectarlas al problema económico, ha sido la economia politica que, como su nombre lo indica, es una economía al servicio de la polis, de la colectividad, de los intereses humanos, tanto materiales como espirituales. La moderna economía política recoge el anhelo de justicia y lo manifiesta en cada uno de sus problemas, desentrañando el fondo humano y humanista que hay en ellos, para reafirmar una vez más el sentido moral de la conducta. Así reconocemos el trasfondo ético en ese terreno, tan vivamente como en çualquier otro, haciendo posible la 
identificación de economia politica y economia ética, que surge como remate de nuestras consideraciones.

La compleja problemática que involucra el propósito de establecer un sistema para lograr la más equitativa repartición de la riqueza y contribuir al bienestar y al progreso del hombre, ha sido abordada en forma disciplinaria por una ciencia como es la economía politica; según lo indica el nombre esta ciencia no se limita a teorizar en forma abstracta sobre los sistemas económicos sino propende a la instauración de un sistema justo que se ponga al servicio de la humanidad para contribuir a la realización de sus más caros intereses.

El sistema de la economía política tiene como base la aceptación de que el proceso económico está ligado estrechamente a los demás fenómenos que acontecen en la vida social y no puede ser desligado ni teórica ni prácticamente so pena de mutilar el sentido de todos los acontecimientos sociales.

Ahora bien, dentro de ellos se encuentra el legítimo anhelo de superación que envuelve al proceso histórico de la humanidad, teniendo en la cima de sus perspectivas al conjunto de valores que constituyen la meta ideal en la actividad humana. Cada uno de los valores en sí mismo, y todos ellos en conjunto, constituyen el carácter distintivo de la ética, que consiste en el valor bondad. Efectivamente, los valores se postulan por ser buenos, y justifican su realización por la bondad que contienen; son buenos en sí mismós y también en la medida que contribuyen al bịenestar del género humano, proporcionándole un horizonte cada vez mayor de progreso y bienestar en todos los órdenes de la existencia. En estas condiciones, la economía política es una ciencia humanista y participa de los intereses que concurren a ambas disciplinas, la economía por una parte, y la política por la otra, reconociendo como denominador común de sus intereses al núcleo sustentante de los valores éticos.

El punto de vista diferencial de la economía mecánica, considerada como disciplina técnica de producción y administración, y la economia politica en su calidad de ciencia humanista que vela por la equitativa distribución del patrimonio de la humanidad, radica en que mientras la economía del primer tipo se circunscribe a establecer la eficacia del sistema productivo, de parecida manera a como proceden las ciencias de causalidad, la del segundo tipo se plantea finalidades axiológicas que trascienden el marco estricto de la eficacia para proyectarse en el dilatado horizonte de la justicia. La economía mecánica actúa más del lado causal de las ciencias naturales que en el dominio teleológico de las ciencias sociales y humanistas, donde encaja con toda propiedad la economía política. Así pues, la disyuntiva que tiene ante sí el economista actual se traduce en la posibilidad de buscar simplemente la eficacia del sistema o procurar la justicia de sus finalidades, bi- 
furcándose en la dualidad de intereses que corresponden al dominio de la naturaleza y de la sociedad respectivamente.

Es necesario señalar que la efectividad misma no es el prototipo de la economía, si no le acompaña el principio ético de la justicia. Han existido sistemas económicos de gran efectividad que, sin embargo, son injustos en sí mismos y se destinan a propiciar causas de evidente injusticia; en tales casos la efectividad del sistema se pone al servicio de intereses particulares, con detrimento y lesión de los intereses sociales que tienen la representación de la mayoría.

Por ejemplo, el sistema esclavista es sin duda muy eficaz para obtener elevada producción, puesto que se explota a los esclavos hasta el desfallecimiento, con un mínimo de erogaciones y de compromisos; sin embargo, nadie sostendría en la actualidad que dicho sistema es justo, por más que en el aspecto netamente económico pueda ser muy eficaz. Análogamente, algunas dictaduras se han encumbrado por la acción de un sistema económico eficacísimo, pero lo han sido a base de menoscabar o nulificar los derechos humanos, sobre sistemas de explotación inicua, y su rendimiento se destina a enriquecer a las oligarquias gobernantes que imperan de manera omnímoda en los sistemas dictatoriales.

Aquí se ve la importancia de aparejar el concepto ético de la justicia al principio económico de la eficacia; de hecho han estado divorciados en la mayor parte de la historia, originando profundas desavenencias que motivan la constante reacción de cariz ético, político, jurídico, económico y sociológico, en el cual se enmarcan los movimientos progresistas y revolucionarios que buscan no solamente una economía más eficaz, sino también una economia sin tener en cuenta los coeficientes de valoración social, que resultaría en nuestro tiempo inoperante y absoluta, pues cada pueblo al tener conciencia de una situación injusta promueve las reformas pertinentes, ya sea por el camino pacífico de la legislación o por el violento de la lucha armada. La historia está llena de ejemplos que corroboran este aserto y su lección nos hace concluir que no basta la efectividad de un sistema económico cuando se pone al servicio de una minoría, sino que debe ser eficaz en el aspecto material y justo en el aspecto moral, destinándose a satisfacer las necesidades de la sociedad, a promover su bienestar y elevar su nivel de vida.

El centro de las preocupaciones en la moderna economía política es el concepto de propiedad, y expone el índice real que alcanza en un sistema determinado la justicia económica. En efecto, si la finalidad de la economía consiste en la producción de bienes materiales, el efecto de dicha producción es la pertenencia de los bienes producidos; de ahí la importancia que tiene el concepto de propiedad.

Dicho concepto ha variado notablemente en el transcurso del tiempo; 
así, en la Antigüedad se admitía el derecho a que un solo individuo poseyera la totalidad de los bienes de una colectividad, y transmitirlo por herencia a sus descendientes; en cambio, las doctrinas contemporáneas propugnan por una consideración igualitaria de los hombres, concediendo a todos el mismo derecho a participar en la riqueza colectiva y reduciendo al mínimo la propiedad privada, asi como su transmísión hereditaria. Es obvio que la justicia está del lado de las doctrinas modernas, puesto que es más justa la idea de conceder los mismos derechos a todos los hombres que otorgar prerrogativas a unos cuantos, sobre todo a uno solo, que lo recibiría por la fortuita concesión de su progenitor. El cambio que se ha experimentado desde las antiguas monarquías que acostumbraban el traspaso hereditario y matrimonial de países e imperios completos, hasta la situación que priva hoy día en la conciencia política de los pueblos, ha registrado una transformación radical en los conceptos políticos, sociológicos, económicos, e inclusive religiosos, teniendo como base la idea ética de la justicia que, aplicada al campo de la economía, se traduce en la equitativa distribución de la riqueza, en la justa retribución al trabajo, en dar las mismas oportunidades a todos los individuos.

La desigual posesión de bienes materiales motivó una continua ola de protestas por parte de quienes la consideran injusta, sosteniendo que en vez de ella debe imperar una equitativa distribución de la riqueza.

Desde luego, un clamor de esta naturaleza no obedece exclusivamente a razones de orden moral, que se manifestarian exclusivamente como el preludio hacia un injusto estado de cosas, simplemente por el hecho de ser injusto. El motivo es más profundo y sobre todo, más actuante, pues el hecho de que grandes cantidades de riqueza se encuentren en un reducido número de manos tiene como directa consecuencia que la gran mayoría de los hombres carezcan aun de lo más necesario. Si la riqueza pública fuera tan abundante que permitiera un nivel suficiente para el pueblo y al mismo tiempo tolerara la gran concentración de riquezas en pocas manos, la protesta no tendria la magnitud ni la violencia que ha adquirido, cuando se manifiesta tan drásticamente como sucede, por ejemplo, en la revolución; un movimiento revolucionario se inspira en razones de tipo social, político e ideológico, pero evidentemente obedece a requerimientos de orden económico, y por cierto a los más urgentes, que exigen un nivel de vida suficiente para la población. El sentido de la protesta se vierte también en lo jurídico, alegando la injustificación de los grandes capitales que se han formado a costa del trabajo y la explotación del pueblo; de ahí la necesidad de revisar el concepto de propiedad, que es uno de los problemas capitales en la economía política de nuestro tiempo. 
Vamos a tratar ahora el problema que surge cuando la convicción ética quiere elevarse a la categoría de mandato social respaldado por la ley; es bien sabido que dicha categoría corresponde al derecho, de suerte que el problema de referencia consistirá en el tránsito de lo ético a lo jurídico, de la norma acatada por convicción al mandato exigido por la ley. En dicho tránsito se persigue la máxima objetividad moral, expresándola en la normatividad del derecho para consagrar la validez intrínseca de la idea moral mediante su justificación en la universalidad jurídica de la ley.

Esta relación entre ética y derecho, así como el tránsito correspondiente, tienen por denominador común la admisión de un deber ser normativo frente al ser fáctico. Ese carácter es el que permite el tránsito a que nos referimos, así como la homogeneidad en los dos sistemas -el ético y el jurídico- que se requiere para efectuar dicho tránsito, que sería imposible si no hubiera entre ambos la analogía de funciones que traduce al deber ser en el común carácter normativo de la ética y el derecho. Ambas disciplinas se proponen dictar una norma que oriente a la conducta del hombre, y por eso recaen bajo la jurisdicción del deber. Hablando en rigor, el derecho no es más que una ética objetivada en la ley, mientras que la moralidad es la captación subjetiva de una norma, que por serlo tendrá, cuando menos potencialmente, cierta virtualidad jurídica. Además de este carácter común, tanto la moral como el derecho poseen una propiedad altamente significativa, que consiste en la facultad de proyectarse en todas las manifestaciones del hombre, esto es, en la totalidad de su conducta. Para acentuar con mayor énfasis la similitud entre la moral y el derecho diremos que ambas figuran como teoria de la conducta, cubriendo cada una un aspecto esencial de la misma.

La moralidad y el derecho tienen de común el ocuparse del comportamiento y ambos tienden a regularlo por medio de normas, por cuya razón a la conducta regulada, ya sea moral o jurídica, se conoce como conducta normativa. La norma es un ordenamiento que señala el deber ser de la conducta y al convertirse ésta de fáctica en normativa, se encamina a realizar un deber ser, o simplemente un deber. La formulación de la norma es indispensable para orientar al hombre hacia una finalidad superior, cada vez más elevada.

Ahora bien, existe una dificultad para llevar a cabo dicha conducta y es la divergencia que existe generalmente entre lo que el carácter demanda por temperamento y lo que la norma prescribe por ordenamiento. Esta divergencia puede ser mayor o menor, dando margen a una abierta aceptación de la norma por parte del individuo; tal aceptación voluntaria se designa generalmente como convicción. Subrayaremos que la manera de 
acatar una norma es definitiva para el establecimiento de la disciplina correspondiente.

Los mandatos de la conducta, como todo acto cultural, tienen origen en la interioridad del espíritu, siendo fundamentalmente de naturaleza individual y tienden a proyectarse en todos los seres humanos; la razón exige que si una norma es justificable en su validez, deberá ser acatada por todo el mundo. Este alcance sobre un cierto número de actos o de individuos, es la extensión de la norma, que se conoce también como jurisdicción, y se relaciona directamente con su origen; en la moralidad este origen es la conciencia subjetiva y tiene forzosamente un sentido individual mientras en el derecho el origen es la conciencia social y por ello se reviste con una jurisdicción objetiva.

Ahora bien, la norma se prescribe para ser acatada en la realización de la conducta; pero ello no siempre sucede, por el contrario, se producen continuas violaciones que generalmente obedecen a la dificultad inherente al acatamiento del mandato. Cuando éste no es obedecido, se produce una violación de lo que está indicando en la norma, y en tal caso amerita una sanción que es la pena o castigo señalado para los transgresores.

Resumiendo lo que acabamos de indicar, tenemos fijadas las condiciones de la conducta normativa, y son las siguientes:

a) Establecimiento de la norma.

b) Forma de aceptación.

c) Jurisdicción o extensión explicativa.

d) Origen que determinó su creación.

e) Violación, o sea la conducta negativa.

f). Pena o castigo impuesto como sanción.

Veamos ahora cuáles son las repercusiones que tienen dichas categorias en la relación de ética y derecho.

Hemos señalado la semejanza, pero, ¿cuál es la diferencia entre la moral y el derecho? Sabemos que la moralidad es un sistema ético, acatado por convicción del deber, mientras que el derecho se promulga en forma coercitiva mediante un ordenamiento que impone el Estado a los miembros de una colectividad. Esa distinción indica el fondo interno y personal que tiene la norma ética, contrastando con el carácter abierto e impersonal que exhibe el derecho. De ahí proviene también la fuente originaria que, en el caso de la moralidad, es la conciencia individual, mientras en el derecho es el Estado, que formula las leyes y vigila su observancia, sancionando la violación cometida en forma de actos ilegales, ya sea mediante infracciones económicas o castigos corporales, que pueden llegar incluso a la pena de muerte. En cambio, la violación de una norma ética tiene una consecuencia básica individual, que consiste en el arrepentimiento de haber cometido una falta a la convicción que uno mismo había aceptado; naturalmente, 
cuando no existe la conciencia de haber cometido la falta tampoco se produce ningún arrepentimiento, de suerte que la condición básica de la acción moral es la conciencia de la norma y su consiguiente aceptación, mientras que el derecho actúa sobre los individuos aunque éstos no lo quieran reconocer.

Son varios los aspectos en que se distinguen la moral y el derecho y, por otra parte, son los mismos aspectos en que se asemejan, puesto que a ambos convienen las categorías de normatividad que señalamos en el párrafo anterior. Así se funda una correlación entre ética y jurisprudencia, que tiende, por una parte, a unificarlas, y por la otra, a distanciarlas, generando una contradicción que ha producido gran número de conflictos a los estudiosos de la moralidad, de los cuales nos ocuparemos en el presente artículo. Por lo pronto, señalemos el distingo anterior en el siguiente cuadro:

$\begin{array}{lll} & \text { MORALIDAD } & \text { DERECHO } \\ \text { Norma } & \text { Convicción } & \text { Ley } \\ \text { Aceptación } & \text { Voluntaria } & \text { Impositiva } \\ \text { Jurisdicción } & \text { Individual } & \text { Colectiva } \\ \text { Origen } & \text { Conciencia } & \text { Estado } \\ \text { Violación } & \text { Falta } & \text { Delito } \\ \text { Pena } & \text { Arrepentimiento } & \text { Sanción }\end{array}$

La relación más importante que se establece entre la ética y el derecho consiste en la idea que dirige la formación del derecho mismo, y puede reducirse en esencia a la que rige también en la moralidad, pues no obstante la diferenciación que hemos indicado, y aun concediendo que la acción jurídica se efectúa en un sistema absolutamente formal, la idea que orienta la formulación de las leyes no puede ser otra que la siguiente: legislar para convivir en paz por medio de la justicia.

Observemos cuáles son los elementos que participan en nuestra definición. El primero de ellos es legislar. Efectivamente, el derecho es ante todo legislación; las leyes son normas que se promulgan como mandatos obligatorios y han de ser acatados con independencia de que el individuo los quiera reconocer o no, e inclusive, en el extremo de la formalidad jurídica, se exige su observancia aunque el individuo los desconozca, lo cual resultaría inverosímil en el caso de la moralidad. Sin embargo, esta necesidad formal de obligatoriedad en el derecho se comprende porque la conducta ha de acatar algún ordenamiento, y éste debe imponerse necesariamente a los miembros de la colectividad.

Ahora bien, el derecho no se justifica por sí mismo; para explicar por qué se formulan las leyes no bastaría con responder simple y sencillamente: 
para formular leyes. Esto equivaldría más o menos a sostener que el derecho es un entretenido juego de legisladores. Lejos de ello, las leyes tienen un objeto primordial, que es regular la convivencia para hacerla posible, puesto que sin una norma que deban todos acatar la convivencia tornaríase insoportable. De ahí, pues, que el derecho se encuentre al servicio de una finalidad más elevada que la mera formulación de leyes, a saber: la convivencia humana.

Empero, tampoco se define la esencia del derecho con la sola indicación del servicio a la sociedad, omitiendo las finalidades de la conviveecia; su base estructural y su tendencia ingénita consiste en vivir en paz, o lo que equivale, simplemente en vivir, puesto que lo contrario de una convivencia, una disvivencia, es tanto como ruptura de la armonía y la solidaridad en el convivir. Así pues, el derecho debe producir normas que permitan la coexistencia pacífica, y eso lo obtiene solamente cuando se pone al servicio de otra finalidad más elevada, como es la realización de la justicia para el progreso del hombre. He ahí la finalidad suprema de la ley, el objetivo sin el cual carecería no solamente de sentido humano sino también de actuación real, pues cuando el derecho es vehículo de injusticia acaba provocando una reacción adversa que promueve su transformación, ya por sistemas pacíficos, como en la técnica parlamentaria, o por medios violentos, como sucede en la revolución. Si no existiera la idea de que la organización jurídica debe quedar al servicio de los valores humanos, principalmente de intereses tan caros como la paz, el bienestar, la justicia y el progreso, no se habría planteado ninguno de los problemas que envuelven continuamente a la legislación, y que se traducen en preocupaciones de orden social, económico, político, y sobre todo, ético, pues al postular la realización de un derecho justo se está reafirmando el nexo que tiene con la moralidad.

Así tenemos que, en el fondo, la idea del derecho coincide con la moral, puesto que ambos procuran la bondad y la justicia; si alguna diferencia subsiste entre las dos disciplinas deberáse a la irreductibilidad de la conciencia individual frente a la normación objetiva de las leyes. $\mathrm{Y}$ precisamente en virtud de que subsiste un tal distingo, surge el problema a que nos referimos, originado por dos términos opuestos como son la identidad ideal del derecho y la moralidad, y la diferencia real de la subjetividad inherente a la primera y la objetividad característica del segundo.

De esta doble relación que existe entre la idea de justicia y las leyes positivas, deriva la dificultad de su acoplamiento, que designamos con el nombre de aporia ético-juridica; sabemos que aporía significa dificultad y tal es justo la índole de la relación establecida, una dificultad en el acoplamiento de la ética y el derecho, de lo que se considera justo, por una parte, y lo que es necesario imponer bajo un sistema coercitivo, por la otra. 
Para que exista esa dificultad es necesario, ante todo, que se establezca la relación correspondiente, sin la cual carecería de sentido hablar de un problema, en cuyo caso ambas disciplinas no tendrían conexión alguna; ahora bien, la dificultad surge de que no son idénticas, y aún más, de que la moralidad y el derecho tienen considerables puntos antagónicos. Así, el tema que nos ocupa en estos momentos puede formularse de la siguiente manera: ¿Cuál es la dificultad que se presenta para que el derecho sea justo? También la pregunta inversa es válida: ¿Qué problema involucra la formulación jurídica de una idea moral?

La dificultad principal estriba en que el derecho no siempre tiene en cuenta razones de moralidad, que deberían promoverlo a realizar la verdadera justicia; en numerosas ocasiones formula leyes sin preguntarse por el valor humano que contengan, y sobre este camino suele llegar a francas comisiones de injusticia.

Para resolver esta aporía es necesario el concurso de los juristas al lado de los sociólogos, de los filósofos, los políticos, psicólogos y antropólogos, y en general, de quienes se ocupen de estudiar la naturaleza y la conducta del hombre desde cualquiera de los numerosos ángulos que presenta. El error que se ha cometido con demasiada frecuencia en los sistemas morales y procesales consiste en la excesiva idealidad de los primeros y el radical formalismo de los segundos, cosa explicable por el aislamiento en que se encuentran. Para resolver la aporía ético-jurídica es indispensable su comunicación y el mutuo auxilio de sus cultivadores, con el consiguiente ensanchamiento de sus horizontes, ya que en último término la aporía no es exclusivamente de raigambre ética y jurídica, sino también sociológica, antropológica, psicológica, religiosa, histórica, etc., tocando todos los intereses que concurren a la vida humana.

Esto es lo que sucede cuando el derecho se pone al servicio de intereses particulares, con frecuencia de oligarquías y plutocracias que dominan el gobierno de un país mediante la fuerza y en contra de los principios humanos. A nadie escapa que las dictaduras recurren continuamente a este medio para afirmarse en el poder empleando un sistema jurídico que en el aspecto netamente formal tiene absoluta vigencia, por más que su contenido sea injusto y nugatorio de los derechos humanos. ¿Qué razón más poderosa puede encontrarse para explicar esta disparidad entre el derecho y la moral que la deliberada intención de hacer un derecho injusto? Si un gobierno impone sus leyes por la fuerza, de nada servirá argumentar en pro de la justicia, ya que a sabiendas quedará reducida a las prescripciones de un derecho injusto, y tampoco tendrá efecto insistir en justificarlo por medio de un valor si anticipadamente se reconoce la inutilidad de los valores, e incluso se les violenta ex profeso para servir a intereses inconfesables que suelen predominar en la jurisprudencia dictatorial y oligárquica. 
La razón de este desacato es múltiple, y consiste, para decirlo en una palabra, en el aspecto negativo de la humanidad, que se refleja directamente en el desajuste de dos disciplinas que deberían ser gemelas; el margen de injusticia que priva en las leyes débese a la imperfección de la naturaleza humana, que se traduce en la incomprensión mutua, en el antagonismo de los individuos y las colectividades, y sobre todo, en el afán de preponderar sobre los demás, que ha llevado a la opresión y la explotación desenfrenada del hombre por el hombre. Este desequilibrio, producto de las imperfecciones y los defectos del ser humano, se ha consagrado en el derecho en forma de leyes injustas; permitiendo, impulsando y aun exigiendo, la comisión de las peores inmoralidades. El sistema de las leyes se ha convertido asi en patente oficial de un lema conocido y aceptado desde la Antigüedad: el hombre es el lobo del hombre.

Pero aun en el caso de que el sistema legislativo no estuviera al servicio de intereses particulares y violatorios de la justicia, hay otra gran dificultad para acoplar el derecho a la moral, y consiste en la variabilidad de esta última, o sea la dificultad para establecer universalmente un sistema moral. Sabemos que esta variabilidad obedece a numerosos factores, y que en última instancia queda circunscrita al ámbito individual, cuyo carácter le riñe en forma terminante con la socialidad del derecho. Es natural que si entre los individuos privan diferencias irreductibles en el orden ético, deban ellas traducirse forzosamente en desajustes con la legalidad, originando un gran número de conflictos ético-jurfdicos. Pero aun así, en la gran mayoría de los casos el derecho acepta el tipo de ordenamientos que se imponen como normas básicas en la moralidad, y así tenemos que en la legislación de todos los países civilizados se reconoce, por ejemplo, la prohibición de matar, robar, violentar los derechos humanos, aunque algunas lagunas jurídicas permitan la comisión de atropellos que constituyen una preocupación constante de sociólogos, juristas y moralistas, simultáneamente empeñados en la supresión de la injusticia legal, por más arraigada que estuviere.

Ahora bien, esta variabilidad es hasta cierto punto insuperable en lo que se refiere a la diferencia de los caracteres, pero no debe tomarse como absoluta ni irreductible a la homogeneidad de obligaciones y derechos que proclama la norma. Sin pretender la desaparición de los caracteres personales, incluso los más individualistas, la moral debe fincarse sobre bases de objetividad para reducir al máximo sus coeficientes variables, penetrando en el terreno de los deberes sobre la base de un inviolable respeto al prójimo. Así tenemos a la estabilidad ética del hombre amparada en la homogeneidad social que se traduce en la solidaridad colectiva, cuyos efectos son de todo punto saludables para el desenvolvimiento del individuo. Pero una firme conciencia de solidaridad se obtendrá sólo mediante la más intensa campaña educativa, que le enseñe cuáles son las indispensables limitaciones 
a su libertad natural y cómo puede estar de acuerdo con el prójimo mediante el reconocimiento objetivo de los valores. Este acuerdo es casi utópico, pues lo que impera es precisamente el desacuerdo en la noción de los valores; pero de cualquier forma es el único camino para resolver la excesiva variabilidad de las convicciones morales en el seno de una misma colectividad.

La relación ético-jurídica nos lleva directamente al caso de violación que referimos anteriormente, el cual reporta una falta para la moralidad y un delito para el derecho. La aporía señalada desemboca en la consideración recíproca de ambos casos, planteados respectivamente en las siguientes preguntas:

¿Hasta qué grado puede ser falta a la moralidad un delito cometido? ¿Hasta qué punto puede o no ser delictiva una falta a la moralidad? Esta situación tiene, como puede observarse, un doble alcance, y concierne a ambas disciplinas puesto que son indesligables el coeficiente moral y el legal; esta simultaneidad se traduce en el continuo acudimiento a razones, de orden jurídico y sociológico en la moralidad, y de manera recíproca, a fundamentaciones éticas para comprender la razón profunda del derecho.

De acuerdo con esta dualidad de aspectos la conducta normativa puede clasificarse en los siguientes territorios:

a) Normas éticas ajurídicas.

b) Normas jurídicas amorales.

c) Normas éticas antijurídicas.

d) Normas jurídicas inmorales.

e) Normas éticas y jurídicas.

f) Normas inmorales y antijurídicas.

Veamos someramente cuál es el significado de esta clasificación.

a) Normas éticas ajuridicas. Se refiere a los actos que son incluidos estrictamente en la moralidad como producto de una convicción neta del individuo, sin que su efectuación haya sido prevista por la ley. Un acto de caridad, por ejemplo, es producto de la conciencia moral del individuo, y lo llevará a cabo siempre y cuando tenga la convicción de hacerlo, sin que el derecho le impida o le obligue a efectuarlo.

b) Normas jurídicas amorales. Entendemos en esta clasificación a los ordenamientos que tienen un alcance legal y no tocan los intereses de la moralidad, refiriéndose exclusivamente a cuestiones de carácter técnico. Por ejemplo, una ley que se refiera a las Comunicaciones constituirá el fundamento legal del correspondiente sistema y se desenvolverá con total independencia de la moralidad.

c) Normas éticas y antijuridicas. Son los mandatos que el individuo se dicta a sí propio, o recibe de una cierta filiación ancestral o ambiental, promoviendo actos contrarios a la ley. Por ejemplo, un hombre con inquietudes políticas podría violar alguna ley para desplegar ciertas actividades y lo ha- 
ria movido por convicciones que para él poseen un valor ético, aunque su actitud fuera contraria a la ley.

d) Normas juridicas inmorales. Es el caso inverso, y en él recaen los ordenamientos del que hemos llamado "derecho inmoral"; son prescripciones que obedecen a las circunstancias negativas que hemos comentado. Por ejemplo, el simple acto de emitir con libertad una opinión puede tomarse como actividad subversiva y caer en el género de los llamados "delitos políticos", que desgraciadamente han sido mancha de las leyes y bochorno de numerosos gobiernos.

e) Normas éticas y juridicas. En este grupo hacemos incluir los casos que por su evidente necesidad y su innegable valor humano han sido incorporados simultáneamente a las prescripciones éticas y las jurídicas. El ordenamiento bíblico, que dice "No matarás" es uno de los más aceptados por el sistema moral y legal de cualquier país civilizado.

f) Normas inmorales $y$ antijuridicas. Se trata de las disposiciones erradas que el individuo adopta por creerlas de conveniencia propia, a sabiendas de que comete una falta a sus convicciones y una violación a la ley; cs el caso típico de la delincuencia, y obedece, por regla general, a imperiosas necesidades económicas, a un serio desajuste con el medio ambiente y a una marcada distorsión en la personalidad. El individuo que se propone hacer fortuna por medios ilícitos tiene como norma de vida una actitud ilegítima en relación a la moral y delictiva frente a las leyes sociales.

En estos seis grandes apartados se puede establecer una clasificación de la conducta normativa, atendiendo a las diversas posibilidades que involucra la simultánea acción de los factores éticos y jurídicos. Al plantear este problema nos encontramos en el desenlace de nuestras reflexiones, toda vez que lo hemos proseguido a partir de sus causas, quedando por observar cuáles son sus consecuencias; y como ya nos hemos ocupado de las cuestiones éticas, veamos ahora lo que sucede en el campo del derecho.

La conclusión que obtenemos al considerar el ingrediente ético del derecho es que, de acuerdo con un criterio estrictamente formalista, no debería existir ningún atenuante de responsabilidad en el juicio penal, pues bastaría la simple violación de una ley para establecer automáticamente la pena respectiva. En cambio, conforme al criterio material todos los actos punibles admiten ciertas consideraciones concretas, ya sean atenuantes o agravantes, pues en todos los casos hay factores realistas que los determinan. Los actos ilegales se sitúan en una escala gradual de responsabilidad, según el nivel de conciencia que muestre el sujeto que los comete.

Pueden producirse fundamentalmente tres casos, según el grado de responsabilidad: la contravención, el delito y el crimen; para apreciarlos debidamente es indispensable acudir a conceptos éticos y jurídicos, como se verá a continuación. 
a) La contravención es simplemente un acto que va en contra de las estipulaciones legales, y suele cometerse ignorando la existencia o el alcance de dichas estipulaciones.

b) El delito es un acto ilegal que se efectúa conociendo su ilegalidad, pero con algún atenuante, casi siempre de naturaleza moral, económica, política, sociológica, religiosa, etc.

c) El crimen es la comisión de un acto inmoral y casi siempre ilegal, que tiene profundas repercusiones éticas; se comete a sabiendas de causar grave daño a terceros, de donde la inmoralidad que representa.

De acuerdo con el criterio que sustentamos, toda contravención es ilegal pero no puede ser inmoral, porque es simplemente una contravención de hecho y en asuntos de leve repercusión; mientras que el delito, siendo también ilegal, puede o no ser inmoral, de acuerdo con el sistema ético que se profese; finalmente, el crimen es siempre inmoral y casi siempre ilegal, por lo que constituye la más grave falta que pueda cometerse.

Existe, sin embargo, una apreciación ética del crimen que llevaría a una profunda divergencia con respecto del derecho, dándose los casos de crímenes inmorales, pero legales, o de casos tenidos juridicamente como criminales pero que pueden obedecer a una profunda y auténtica convicción moral. Esta apreciación sorprenderá a quien no se haya percatado que puede haber, y de hecho hay, crímenes que están al amparo de la ley, y que incluso pueden merecer la aprobación de la sociedad desde el punto de vista jurídico y sociológico. Sin embargo, en términos generales un crimen se considera jurídicamente como un delito grave y cometido a sabiendas de su negatividad, o sea con la voluntaria deliberación de la persona para hacer un grave daño a terceros. Por otra parte, desde el punto de vista estrictamente ético, las contravenciones son simples faltas amorales, mientras que los actos que son delitos y aun crímenes en el aspecto legal, pueden ser en determinado momento justificables y plausibles, para un determinado sistema ético, de acuerdo con la idiosincracia que rija en un individuo o en una colectividad.

El inevitable desajuste que entraña la aporía ético-jurídica tiende a resolverse mediante la humanización del derecho, y recíprocamente, en la codificación jurídica de la moralidad; están empeñados en tan meritoria faena los filósofos y moralistas, por una parte, así como los sociólogos y juristas, por la otra, conscientes de la necesidad que hay de superar dicha dificultad; es de suponer que tales esfuerzos logren su propósito, o sea una mayor aproximación de ambas disciplinas, con el consiguiente beneficio para el bienestar y el progreso de la humanidad.

El desajuste que provoca la aporía ético-jurídica ha originado muy profundos problemas en incontables casos de la conducta. Ahí están los actos penados por la jurisprudencia, pero requeridos por cierto tipo de moralidad, como son las actividades de orden político y social que se promueven por 
virtud de una convicción ética, aunque se opongan a las leyes; por ejemplo, un gran número de los llamados "delitos políticos" obedecen a una ideología que se apodera del individuo y lo compele a realizar ciertas actividades que pueden eventualmente estar en contra de la ley. También el religioso que se viera constreñido a violar algunas disposiciones sobre cultos, podría tal vez hacerlo por una sana convicción personal, entrando en un inevitable conflicto con la ley. Un gran número de profesionistas -médicos, abogados, maestros, etc. - están en conflictos parecidos al cometer ciertos actos que van de acuerdo a sus convicciones, pero en contra de las leyes. $\mathrm{Y}$ así sucesivamente.

Por otra parte, el caso contrario corresponde a los ordenamientos legales que han sido entronizados para servir intereses morales, casi siempre en perjuicio del pueblo. Los gobiernos dictatoriales y oligárquicos promueven jurisprudencias represivas para mantener a la ciudadanía en un estado de servidumbre que les permita continuar en su inmoral cometimiento, contando para ello con todo el aparato ejecutivo, legislativo y judicial, que requiere el eficaz funcionamiento de una maquinaria legalista, por más que su fondo ético y social fuere en todos los aspectos negativo. Además de ello, numerosos delitos se cometen al amparo de la ley, llegando inclusive a crímenes y atentados que han sido el acompañante de numerosas actuaciones inmorales. ¡Y qué decir de la prevaricación, el lucro desenfrenado a que se dedican algunos individuos, para quienes la política no es sino el más fabuloso de los negocios! También en este caso la ley suele acudir en su auxilio, no solamente para protegerlos en el cometimiento de sus desmanes, sino para garantizar la impunidad legal, aun después que hubieren abandonado sus puestos de mando.

Por todo ello, las consideraciones al problema ético-jurídico deben estar en su primer plano de importancia en las cuestiones morales. Creemos haber dado alguna luz al respecto y queda pendiente, desde luego, su aplicación a los casos concretos, que son en número incontable y saturan todos los planos y regiones de la existencia. 